\title{
«La única verdad es la realidad»: apuntes sobre la noción de «historieta realista»
}

ABSTRACT: The label «historieta realista», in Spanish, is used to define a section of the field of production of comics. This paper analyzes to what style of drawing does the term «realistic» apply, and addresses the historical background of this style and the possibility that a comic may be a «realist text». It examines how the «realistic drawing» poses a tension between cartoon and photography.

Keywords: comics, realism, photography, cartoon.

RESUMEN: La etiqueta «historieta realista» se utiliza para definir un sector del campo de la producción de historietas. El presente trabajo analiza a qué estilo de dibujo se aplica el término realista, aborda los antecedentes históricos de ese estilo y la posibilidad de que la historieta pueda constituir un realismo. Se examina el modo en que el «dibujo realista» está en una tensión entre la caricatura y la fotografía.

Palabras clave: historieta, realismo, fotografía, caricatura.

\section{Las palabras y las cosas}

Resulta siempre productivo prestar atención a las etiquetas con que una comunidad se define a sí misma. Esas etiquetas no tienen por qué exhibir una pertinencia teórica o una precisión que pertenecen a otros géneros discursivos, pero muchas veces permiten examinar con claridad el modo en que los integrantes de un campo se ven a sí mismos, la historia de sus prácticas y las perplejidades $\mathrm{y}$ fronteras que perciben. 
En el interior del campo de la historieta, al menos en el ámbito de habla hispana, existe una división que califica no solo estilos diversos, sino que se extiende al campo editorial -en tanto ha definido las características y lectores de las publicaciones-e incluso divide a los productores en zonas percibidas con nitidez. Se trata de la oposición entre historietas humorísticas y lo que, con significativa ambigüedad y abundancia de comillas se conoce como historieta «realista», «seria» o «de aventuras». ${ }^{1}$

La terminología es por lo menos curiosa. La historieta humorística tiene objetivos más o menos evidentes (hacer reír, causar en algún sentido gracia). Sin embargo, es por lo menos extraño incorporar a la categoría de «historieta realista», relatos protagonizados por guerreros sumerios, sujetos inmortales, sobrevivientes de un holocausto nuclear o agentes secretos. La noción de «historieta seria», por su parte, parecería condenar a las historietas que caen bajo esta categoría a un mundo de solemnidad un tanto alarmante.

La terminología ha sido recogida en los estudios contemporáneos sobre historietas, en particular aquellos que provienen de una mirada sociológica (von Sprecher 2007 y 2008, Vázquez, 2010) debido a que, más allá de las ambigüedades que son en buena medida el objeto del presente trabajo, permitió durante muchos años distinguir zonas de la producción que eran a tal punto claras para los autores y los lectores que casi definían profesiones diferentes. La historia de la historieta argentina es ilustrativa al respecto. Hasta los últimos años, en que las fronteras entre ambos estilos $-\mathrm{y}$ los sistemas genéricos y de publicación asociados- se han vuelto porosas, ${ }^{2}$ han sido muy raros los casos de dibujantes que se hayan dedicado alternativa o simultáneamente a la historieta «seria» y a la «humorística». Aunque una revista como Dibujantes haya subrayado que «los dibujantes argentinos formamos una familia» (Vázquez, 2010: 56), queda claro que en esa familia los roles estaban bien definidos. Es cierto que existieron en ciertos momentos revistas que combinaron ambos estilos: el ejemplo más exitoso en Argentina puede ofrecerse con la revista Patoruzito en la década de 1940, que incorporaba en sus páginas tanto las aventuras del indiecito que le daba el título como el Vito Nervio dibujado por Alberto Breccia. Sin embargo, para la segunda mitad del siglo xx la distinción se cristalizó y para las décadas de 1960 y 1970 los

1. En el ámbito de la historieta norteamericana, cuyo análisis es fundamental en la medida en que su influencia conformó buena parte de las tradiciones de la historieta en todo el mundo y en particular en Argentina, la distinción más pertinente parece ser la que separa, más que estilos, medios de publicación: las tiras para la prensa por un lado y el comic book por otro. Sin embargo, la distinción entre estilos gráficos es percibida, y la incorporación de un «dibujo realista» en el mundo del «big-foot cartonny style» ha sido destacada (Harvey, 1994: 116).

2. Quedaría por analizar si la crisis en el sistema de publicación de historietas en la década de 1990 (von Sprecher, 2008 y 2007) ha tenido incidencia en esta permeabilidad estilística. 
territorios quedaron bien delimitados: el humor entraría a las revistas editadas por Columba (D’Artagnan, El Tony, Fantasia, Intervalo) o Record (Skorpio, Pif Paf, Tit Bits) solo en modos ocasionales y casi siempre bajo la forma del cartoon de cuadro único o la tira de prensa norteamericana, y la historieta «seria» quedaría excluida de publicaciones como Tía Vicenta, Mengano, Satiricón o, con alguna excepción, Hum(r). Recién con el cruce de nuevas influencias -la historieta francesa de los setenta, la historieta underground norteamericana y el manga japonés- la distinción entre estilos de dibujo, y la correlación entre estilos y géneros predeterminados empezará a resquebrajarse.

Es necesario realizar una aclaración adicional, que mal mirada podría resultar un oscurecimiento: la distinción se superpone solo parcialmente a otra, la que separa «humor gráfico» de «historieta». Baste revisar las tapas -que hacen justicia al contenido, por lo demás- de los libros de divulgación que Carlos Trillo y Alberto Broccoli -autores de historieta «seria» y «humorística», respectivamente (Trillo y Broccoli 1971 a y 1971 b) - dedicaron al humor gráfico y la historieta a principios de la década de 1970, para percibir que dentro del volumen dedicado al «humor gráfico» aparecen personajes de historieta: esto es, personajes que aparecían en discursos construidos mediante secuencias de imágenes fijas y no solo en cuadros únicos. La secuencia, el uso de ese lenguaje que conocemos como «historieta», no aparece entonces como el rasgo definitorio a efectos de distinguir «historieta» de «humor gráfico», a efectos de clasificar los modos en que los autores entendían su profesión y los lectores sus consumos. Lo que importa, para distinguir historieta de humor gráfico tanto como para distinguir «historieta realista» de «historieta cómica» es un conjunto de rasgos temáticos y retóricos y algunas constantes genéricas pero, sobre todo, un estilo de dibujo.

\section{El dibujo realista}

En aquello que podemos reconocer, más allá de las dificultades para proponer una definición, como «dibujo de historieta seria» o «dibujo realista», es posible detectar dos tradiciones que llegan a puntos similares desde orígenes diversos.

Por una parte, el dibujo en la historieta moderna ${ }^{3}$ surge de la extensa tradición de la caricatura, entendida en un sentido muy amplio: la tradición de alterar deliberadamente las proporciones del dibujo en relación con aquello que se considera

3. Entiendo como «historieta moderna» aquellas producciones que se originan en el siglo XIX y en medios impresos, sin entrar en el debate acerca de si puede considerarse «historieta» cualquier producción que organice imágenes en secuencia, en cualquier momento histórico, impresa o no. 
aceptable en una época determinada. Valga la definición del Grupo $\mu$ (1993: 279): «[la caricatura] Es una figura en la que uno o varios elementos del significante del enunciado son producidos por una transformación que lo pone, o los pone, en evidencia con relación a los restantes elementos». Es importante destacar en la definición que, como el mismo texto señala (p. 278), «decir que la caricatura acentúa los efectos "cómicos" o "desagradables" cae dentro del orden del ethos, y no debe intervenir aquí: vaciemos pues, la palabra de toda connotación ligada al uso de esta figura en los géneros localizados, tales como la caricatura política».

Lo que me interesa de una definición semejante es su carácter puramente formal, puesto que, si bien en un principio la historieta humorística tendrá, como lo indica la etiqueta, una función cómica -y las transformaciones propuestas en el dibujo se proponen «hacer reír»- ese estilo estará en el origen de una de las líneas de desarrollo del dibujo de la «historieta realista»: la línea que lleva de las historietas primitivas a una adaptación a un modelo distinto, a la construcción de relatos extensos en los que prime la narración sobre el efecto humorístico de corto plazo. Esta evolución dará una de las grandes tradiciones del dibujo de historieta «seria», la que va de Roy Crane a Milton Caniff y luego a Hugo Pratt o Alberto Breccia, a partir de una progresiva adaptación de las figuras cómicas originales -alteradas mediante transformaciones de elementos seleccionados: la lógica del «big foot», las narices exageradas, las cabezas gigantes- a las proporciones transformadas de manera uniforme en todas los sectores del dibujo, aquello que se llamará «realista». Robert C. Harvey (1993: 124) ha examinado con detalle el efecto que, sobre los primeros autores de la historieta norteamericana tuvo la «invasión» de dibujantes provenientes de de la publicidad y la ilustración en revistas: «cartoonist aproximated the ilustrative manner by adapting traditional cartoon styles to a more realistic depiction of people and scenes without entirely abandoning the simplicity of the earlier style». El recorrido estilístico de la historieta japonesa parece haber seguido este camino, a partir de la fuerte influencia que el dibujo de los productos de Disney tuvo sobre Osamu Tezuka, a su vez el padre del manga contemporáneo.

Es justamente esta entrada al mundo de la historieta de estilos de dibujo gestados en la ilustración en los libros, las revistas y la publicidad - y, con diversos grados de distancia, en el acceso a la educación artística formal y el contacto con las artes plásticas reconocidas- lo que constituye la segunda línea que confluye en el dibujo de «historietas realistas». Es interesante notar cómo este estilo -cuya fundación, al menos en la extensión de su influencia, puede datarse en 1929 con el Tarzán de Harold Foster- se liga en un principio a la literatura. Así como las primeras tiras de Tarzán son básicamente cuentos ilustrados, la historieta «seria» argentina será una producción extremadamente literaria, en que la diferencia con el cuento ilustrado radica sobre todo en la organización espacial de la página y en la utilización del globo, siempre enmarcado en extensos textos de apoyo. Solo la 
influencia del cine modificará esta relación, y le dará al dibujo no humorístico un modelo -sobre todo a partir de una conciencia del encuadre y la escena- para que la narración se independice al menos parcialmente de la palabra.

La historia de un estilo, de todos modos, no nos describe ese estilo. Baste la comparación de tres ejemplos de historietas publicadas por editorial Columba, la más longeva y exitosa editorial de «historietas realistas» de la Argentina. Si observamos los trabajos de algunos dibujantes que se reconocen como «realistas», veremos diferencias evidentes. Podemos pensar en dos de los principales dibujantes que se ocuparon de Nippur de Lagash, ${ }^{4}$ Lucho Olivera y Ricardo Villagrán, y notar que el registro gráfico es muy diferente: Olivera, con claras influencias del Mort Cinder de Alberto Breccia, utiliza manchas y claroscuros, y una línea más gestual que la de Ricardo Villagrán, cuyo estilo remite a los modos contemporáneos de la ilustración publicitaria. ${ }^{5}$ Podemos examinar también el trabajo de Carlos Vogt en Pepe Sánchez, ${ }^{6}$ una historieta humorístico-costumbrista, y notar cómo la intención cómica se relaciona con una línea limpia y una trabajo fuerte sobre la gestualidad corporal y facial, lo que da un resultado gráfico muy diferente que el de sus colegas.

Como puede verse, si existe algún rasgo común que unifique estas producciones no radica en las operaciones sobre los signos plásticos. Tampoco depende de la construcción espacial en que se insertan los personajes, que en muchos casos se limita a una simple notación (algún vegetal denota «exterior», algún muro de piedra o un mueble denota «interior»). Primera comprobación, entonces: lo que separa al «dibujo realista» del «dibujo humorístico» parece ser casi exclusivamente la coherencia en la representación de las proporciones de la figura humana.

\section{Límites}

Dos extremos están en los límites del «dibujo realista». La caricatura, por un lado, y la imagen fotográfica, por el otro. Por un lado, la práctica de una trans-

4. Nippur de Lagash, con dibujos de Robin Wood y dibujos de Lucho Olivera, comenzó a publicarse en la revista D'Artagnan de editorial Columba en 1967. En 1972, Ricardo Villagrán se ocupará del personaje, siempre con guiones de Robin Wood, en el comic book mensual dedicado al personaje.

5. La ilustración es, en esos años, otra categoría de calidad: baste citar a Ricardo Villagrán: «Para conservar el lugar que me había ganado en el campo de la ilustración, pedí el mejor precio de la editorial» (Vázquez, 2010: 241).

6. Pepe Sánchez comenzó a publicarse en la revista D'Artagnan de editorial Columba en el año 1975. 
formación parcial, con efectos cómicos o no, pero siempre marcados respecto de un modelo, siempre exhibiendo su carácter de construcción. Por otro lado, la fotografía, la imagen que denota el «estar ahí» del objeto representado, con el consiguiente borramiento de la marca de un productor. Estas tensiones están en el centro de la posibilidad de pensar en una historieta «realista», y explica la inevitable multiplicación de comillas.

Es que si entendemos como «realista» aquel dibujo que busca realizar transformaciones gráficas coherentes en la representación de las proporciones de la figura humana, podemos ver que es un estilo que se enfrenta a cruces complejos, y a veces insolubles, con tres cuestiones básicas. Primero, la idea de una representación perfecta y transparente, que tendría como modelo a la imagen fotográfica: idea que se opone a la noción misma de estilo. En segundo lugar, la construcción de la secuencia en historieta y la posibilidad de invisibilizar las transiciones entre viñetas. Finalmente, relacionado con la cuestión del estilo y las dificultades de una narración invisible, la posibilidad de pensar si el realismo está al alcance de la historieta en tanto lenguaje.

Para empezar, entonces: la fotografía. Es evidente que en la fotografía hay un modelo: incluso literalmente un modelo, en la medida en que los dibujantes realistas debían contar con un archivo fotográfico casi como una condición necesaria para su trabajo, al menos hasta la difusión de la búsqueda de imágenes en la web. Este modelo, sin embargo, no propone una relación sin conflictos.

El dibujante realista se enfrenta a un juicio objetivo de calidad en su producción. Oscar Traversa (1997: 110-117) ha examinado los efectos de la incorporación de la fotografía en un mundo dominado por la ilustración: la publicidad de la primera mitad del siglo XX. Y allí, resalta (Traversa, 1997: 117):

Los juicios de estilo o de destreza, vivos frente a una ilustración, se evanecen parcialmente; un adjudicado fragmento de verdad nos aúna por encima de las fronteras del gusto; una versión, así, del cuerpo de los otros liberada, en una zona al menos, de incertidumbre.

Efectivamente: si el límite es la imagen fotográfica (más aún que la imagen real, en la medida en que las historietas se producen ya en un mundo recorrido por imágenes fotográficas en la gráfica, el cine y la televisión), el dibujo siempre podrá contener un error no buscado, siempre podrá estar mal dibujado o estar desviado hacia la caricatura. El dibujo humorístico, en el límite -baste pensar en Copi- anula esa idea de calidad, o la remite a cuestiones de estilo y no de representación. El dibujo «realista» siempre sufre una sanción relacionada con la verdad, no solo con la belleza. Pero al mismo tiempo, un dibujo siempre tiene estilo: es una fatalidad, y también una necesidad. Una necesidad de los productores -necesidad subjetiva de distinción, pero también necesidad objetiva en la 
medida en que un dibujo reconocible le asegura al autor la posibilidad de no ser sustituido con facilidad por otro que acceda a la misma calidad objetiva- pero es también una condición de los textos. La existencia de un dibujo dice «hay dibujo, no fotografía»: hay texto, producción, sentido, pliegue enunciativo y no realidad: hay símbolo, no indicio. ${ }^{7}$ De manera que el dibujo realista debe someterse, por un lado, a la comparación con la imagen fotográfica, y al juicio de calidad resultante, sin dejar de separarse siempre de la fotografía por el trazo y las decisiones estilísticas.

Por otra parte, la fotografía -aunque no pueda negarse su carácter convencional y la presencia de un punto de vista en el encuadre y las diversas decisiones de estilo que supone- incorpora un intermedio maquínico en la producción de la imagen y, sobre todo, documenta la presencia del objeto. Toda fotografía es, además de un ícono, un índice del objeto representado, que emitió la luz en algún momento concreto y fechable de la historia.

Otra vez Oscar Traversa (1997: 112-113) expresa este punto:

El advenimiento de la fotografía a los medios produce un cambio global en el estatuto de la imagen [...] la fotografía introduce la posibilidad de «penetrar» en elementos particulares, al contrario de los genéricos que nos brindan otros modos de producción de imágenes (la manzana que tengo frente a mí en una fotografía alude a una y una sola que forma parte de las innumeras existentes en el mundo).

El segundo cruce se produce entre el dibujo realista y un elemento fundante de la historieta: la secuencia narrativa y, sobre todo, la puesta en el espacio de esa secuencia. Si existe una especificidad de la historieta como lenguaje, esta es la coexistencia de dos regímenes. Por una parte, lo temporal, dado por la sucesión y el encadenamiento de las viñetas, el tiempo correlativamente sucesivo de la lectura y el tiempo representado en ese encadenamiento. Por otra parte, esa secuencia es expuesta sobre el plano de la página, siempre queda exhibida su construcción: una página de historieta puede leerse como sucesión pero también como unidad plástica.

Si seguimos a Traversa, vemos que el carácter indicial de la fotografía remite a un estar ahí del objeto, que es particularizado. La secuencia pone en crisis este carácter único del objeto representado, con su exposición simultánea sobre el plano de las acciones sucesivas que finalmente son una repetición del objeto.

7. En un trabajo imprescindible para examinar el dibujo en las historietas, Lucas Berone sigue a Masotta en la distinción entre dibujo y fotografía «las imágenes dibujadas [...] se presentan culturalmente como un "código sin mensaje verista" (y la expresión es de Masotta) donde cada rasgo o trazo se nos ofrece como el resultado de la decisión estilística de un sujeto creador (otro sujeto, en todo caso, puesto frente a mí» (Berone, 2011: 95). 
Puede rastrearse en esta incompatibilidad cierta incomodidad de la fotonovela sobre la que sería necesario indagar.

De manera que el «dibujo realista» en la historieta está siempre entre dos orillas a las que tiende pero a las que no puede acercarse sin volverse irreconocible. Cuando tiende a la fotografía, tiende al modo en que lo real más se acerca a su representación gráfica, pero el costo es, por una parte, disolver todo rasgo de estilo - dejar de ser dibujo- y, por otra, poner en evidencia la violenta heterogeneidad que la fotografía exhibe con la secuencia narrativa y con ciertos símbolos fatalmente planos y abstractos, como el globo, las líneas cinéticas, el borde del cuadro o el mismo espacio neutro de la página. Cuando se aleja de la fotografía y se deja llevar por una voluntad de estilo, se acerca a la caricatura, a su opuesto formal. Y pensar en una caricatura realista no es más que una nueva fuente de problemas.

Es posible que el realismo sea sobre todo, como propuso Barthes, una cuestión retórica: la estrategia de acumular detalles concretos a efectos de crear una ilusión referencial: «Semióticamente, el "detalle concreto" está constituido por la convivencia directa de un referente y de un significante; el significado es expulsado del signo» (Barthes, 2009: 220). La estrategia retórica que el cine clásico codificó bajo las formas del montaje transparente: la eliminación de los rasgos que exhiben la construcción o el pliegue enunciativo. Bajo esta idea de realismo, no es imposible pensar en un realismo de guerreros sumerios o sobrevivientes de la guerra nuclear. Sin embargo, la historieta es un medio que difícilmente puede acceder a esa transparencia, y la acumulación de detalles tanto como la búsqueda de ilusión referencia en el nivel del dibujo se muestran como insuficientes, cuando no contraproducentes, cuando se imponen ese objetivo. Insisto: si se acerca a la fotografía, el dibujo exhibe una heterogeneidad con su «puesta en historieta» que muestra, en esa ruptura, el carácter de construcción del discurso. Si se acerca a la caricatura, se resigna a mostrar sus decisiones de estilo, el significante no puede remitir al referente y proponer una ilusión de transparencia, de suceso que se produce sin origen ante los ojos del lector.

La historieta contemporánea ofrece ejemplos de registros gráficos que rompen con la dicotomía entre «dibujo realista» y «dibujo humorístico», porque se hace cargo de estas tensiones. Si no es posible obtener la ilusión referencial mediante un dibujo realista, muchos historietistas, típicamente los dedicados a discursos autobiográficos, apelan a otra ilusión: el trazo, e incluso las carencias técnicas, como índice de «autenticidad»: si hay una marca, es porque hay una relación directa con un sujeto. Otro realismo, si se quiere. ${ }^{8}$ En cualquier caso,

8. Para un análisis más extenso sobre las representaciones del yo en la historieta autobiográfica, remito con cierto pudor a mi artículo «Historietas, autobiografía y enunciación» (Reggiani, 2011). 
los desarrollos de la historieta actual, y el modo en que se va haciendo cada vez menos pertinente la distinción entre «dibujo humorístico» y «dibujo realista», en el nivel de las producciones tanto como en la organización social de los productores, son quizás una muestra de que el «dibujo realista» corre el riesgo de ser el recurso menos realista de los que tiene un dibujante a su disposición.

\section{Referencias bibliográficas}

BARTHES, R. (2009): «El efecto de lo real», en El susurro del lenguaje. Barcelona, Paidós, 211.

Berone, L. (2011): «Sobre algunas premisas teórico-metodológicas para el análisis semiótico de la imagen de historieta» en von SPRECHER, R.; F. REGGIANI (2012) Teorías sobre la historieta. Córdoba, Universidad Nacional de Córdoba, pp. 115-135.

Groupe M. (1993): Tratado del signo visual, Barcelona, Cátedra.

Harvey, R. C. (1994): The Art of Funnies: An Aesthetic History, Jackson, University Press of Mississipi.

RegGiani, F. (2012): «Historietas, autobiografía y enunciación: las increíbles aventuras del yo» en Pepino Barale, A. (ed.) (2012) Narrativa gráfica. Los entresijos de la historieta, México, Universidad Autónoma Metropolitana, pp. 63-87.

Traversa, O. (1997): Cuerpos de papel: Figuraciones del cuerpo en la prensa 1918-1940. Barcelona, Gedisa.

Trillo, C.; A. Broccoli (1971 a): Las historietas, Buenos Aires, Centro Editor de América Latina.

Trillo, C.; A. Broccoli (1971 b): El humor gráfico, Buenos Aires, Centro Editor de América Latina.

VÁzQuez, L. (2010): El oficio de las viñetas: la industria de la historieta argentina, Buenos Aires, Paidós.

Von SPRECHER, R. (2007): «Ejemplo de Campo: la historieta realista argentina» en Teorías sociológicas: introducción a los contemporáneos, Córdoba, Brujas.

- (2008): «El campo de la historieta realista en Argentina y la globalizacion neoliberal», Estudios y crítica de la historieta Argentina, 13, [en línea] http:// historietasargentinas.wordpress.com/2008/08/24/13-el-campo-de-la-historieta-realista-en-argentina-y-la-globalizacion-neoliberal-roberto-von-sprecher/ 